\title{
Polyaniline-CdS Quantum Dots Composite for Mediator Free Biosensing
} Hemant Dhyani $^{1 *}$, Chetna Dhand ${ }^{2}$, B. D. Malhotra ${ }^{2}$ and P. Sen ${ }^{1}$

${ }^{1}$ School of Physical Sciences, Jawaharlal Nehru University, New Delhi-110067, India

${ }^{2}$ Department of Science and Technology Centre on Biomolecular Electronics, National Physical Laboratory, Dr. K. S. Krishnan Marg, New Delhi-110012, India

\begin{abstract}
A novel route has been introduced to fabricate the composite of polyaniline (PANI) and cadmium sulphide quantum dots (CdS-QD) using electrochemical polymerization technique for mediator free biosensing. The synthesis process involves in situ formation of CdS quantum dots that provide template for eletro-polymerization of aniline resulting in nanostructured PANI-(CdS-QD) film deposition on the indium-tin-oxide (ITO) coated glass plate. Transmission electron microscopy and scanning electron microscopy have been used to reveal the formation of CdS-QD and morphological changes involved during incorporation of CdS in PANI matrix and while immobilization of cholesterol oxidase (ChOx). The UV-visible and FT-IR investigations show the formation of PANI-(CdS-QD) composite at the molecular level. This matrix has been utilized for the covalent immobilization of cholesterol oxidase to explore its application for cholesterol sensing. The results of the CV and EIS studies indicate enhanced electrochemical and charge transfer behaviour of the composite. The response studies, carried out using $\mathrm{CV}$ technique, reveal this $\mathrm{ChOx} /$ PANI-(CdS-QD)/ITO bioelectrode to detect cholesterol in the concentration range of 50 to $500 \mathrm{mgdL}^{-1}$ with good detection limit $\left(47.8 \mathrm{mgdL}^{-1}\right)$ and low $K_{m}^{\text {app }}$ value $(0.82 \mathrm{mM})$
\end{abstract}

Keywords: Polyaniline; Cadmium Sulphide; Quantum Dots; Conducting Polymers; Biosensor

\section{Introduction}

Conducting polymers are known to be compatible with biological molecules and also have the quality to efficiently transfer the electric charges produced during the biochemical reactions through their conjugated backbone. In the past few years many conducting polymers have been used with the different prospects for biosensing applications [1]. Among all these polymers, polyaniline is known to be semi-flexible rod and has been found to provide the efficient medium for electron transfer. The chemical and structural flexibility surrounding its amine nitrogen linkages for the immobilization of desired biomolecules has attracted much efforts towards the various applications in the field of biosensing due to its electrochemical, electronic, optical and electrooptical properties [2,3].

Synthesis and functionalization of nanomaterials have aroused much interest due to large surface-to-volume ratio and the quantum confinement effect in semiconductor nanomaterials in which appropriate surface modification by stabilizers can remove localized surface-trap states resulting in increased quantum yield of the excitonic emission. Besides this, quantum dots are known to have extraordinary electronic and optical properties due to their size-tunability, surface capping chemistry, high quantum yield, broad absorption with narrow and symmetric spectra and easy association with the other molecular groups [4]. The semiconductor nanocrystals have been used as fluorescent probes and as active components in nanostructurebiomolecule complexes for biosensor applications $[5,6]$.

In recent years, quantum dots have been used for biosensing due to the electrochemical as well as optical properties $[8,9]$. The bare quantum dots have been used with the principle of fluorescence resonance energy transfer (FRET) and photo-luminescence (PL) quenching treatment to design biosensing assay system for the determination of glucose [10], and the capped QDs have been synthesized in a stable aqueous medium and this system has been used as a fluorescence probe for the mercury ions wherein the optimum fluorescence intensity is proportional to the ion concentration [11]. Furthermore the functional quantum dots have recently been introduced for molecular sieve sensors application [12]. Since, the majority of biosensing applications of quantum dots have been focused using their optical properties and very few results for quantum dots modified electrochemical sensors have been reported till date. Modifying the electrodes by the incorporation of quantum dots promotes direct electron transfer between the biomolecules and electrode surface [13], and also the direct electrochemistry has been reported by preparing the quantum dots/CNT electrode [7].

Among the various quantum dots cadmium sulphide (CdS) (band gap of $2.4 \mathrm{eV}$ ) has been studied with its excellent photoelectrochemical and optical properties [14-16]. Conjugated polymers specially like polyaniline combined with semiconductor nanoparticles (CdS, CdSe and $\mathrm{TiO}_{2}$ ) are widely studied with the remarkable physical, optical, electronic and photoelectric properties [17,22,24]. It has been observed that introducing nanocrystalline CdS on polymer enhances the charges on polymer backbone thus resulting conformational changes in structure of PANI which becomes expanded from its compact coiled form [18]. PANI-CdS composite not only exhibits the enhanced photo and electrical activity but it also increases the life of polymer and have good stability in ambient condition $[21,23]$. These properties of polymer-nanocrystal composite have led to increased interest to explore this PANI-CdS composite for biosensing purpose. Therefore on this way we have devised a novel electrode of PANI-(CdS-QD) composite for biosensing application.

Herein, we report results of the studies relating to the fabrication of PANI-(CdS-QD)/ITO electrode by electrochemical polymerization technique. The composite electrode is shown to have improved responce as well as electrochemical stability due to in situ formation

*Corresponding author: Hemant Dhyani, School of Physical Sciences, Jawaharlal Nehru University, New Delhi-110067, India, E-mail: kashi.hemant@gmail.com

Received October 10, 2011; Accepted December 12, 2011; Published December 16, 2011

Citation: Dhyani H, Dhand C, Malhotra BD, Sen P (2011) Polyaniline-CdS Quantum Dots Composite for Mediator Free Biosensing. J Biosens Bioelectron 3:112. doi:10.4172/2155-6210.1000112

Copyright: @ 2011 Dhyani $\mathrm{H}$, et al. This is an open-access article distributed under the terms of the Creative Commons Attribution License, which permits unrestricted use, distribution, and reproduction in any medium, provided the original author and source are credited. 
of CdS on the PANI backbone which has significantly increased the charge concentration. The novel synthesized PANI-CdS electrode doped with $\mathrm{H}_{2} \mathrm{SO}_{4}$ offers direct electrochemistry in phosphate buffer saline (PBS, $50 \mathrm{mM}$, pH 7.0, $0.9 \% \mathrm{NaCl}$ ) for cholesterol sensing.

\section{Experimental Section}

\section{Materials and reagents}

Cholesterol oxidase (ChOx, EC 1.1.3.6, from Pseudomonas fluorescens) with specific activity of $24 \mathrm{U} \mathrm{mg}$, potassium mono-hydrogen phosphate, potassium dihydrogen phosphate, N-hydroxysuccinimide (NHS), N-ethyl-N0-(3-dimethylaminopropyl carbodiimide) (EDC) has been purchased from Sigma-Aldrich (USA). Aniline was distilled before electropolymerization. Distilled water is from Millipore water purification system. Cadmium chloride $\left(\mathrm{CdCl}_{2}\right)$ and sodium sulfide $\left(\mathrm{Na}_{2} \mathrm{~S}\right)$ have been purchased from Fisher scientific qualizens fine chemicals. Pre-cleaned ITO plates have been used as substrates for the electrochemical deposition of PANI-(CdS-QD) composite.

\section{Synthesis of CdS quantum dots}

For the synthesis of CdS quantum dots, $87.4 \mathrm{mg} \mathrm{CdCl}_{2}$ is dissolved in $50 \mathrm{ml}$ methanol followed by sonication for about 10 mins. $7 \mathrm{mg}$ $\mathrm{Na}_{2} \mathrm{~S}$ is dissolved in $5 \mathrm{ml}$ methanol separately and sonicated. Now $\mathrm{Na}_{2} \mathrm{~S}$ solution is added into the $\mathrm{CdCl}_{2}$ solution with continuous vigorous stirring till the solution turns yellow. The resultant solution is then centrifuged and powder of CdS quantum dots has been obtained.

\section{Fabrication of $\mathrm{H}_{2} \mathrm{SO}_{4}$ doped PANI-(CdS-QD) electrode}

PANI-(CdS-QD) composite film has been fabricated onto ITO glass plates by electrochemical deposition technique in a three electrode cell having $\mathrm{Pt}$ foil as counter electrode and $\mathrm{Ag} / \mathrm{AgCl}$ as the reference electrode. The $50 \mu \mathrm{l}$ distilled aniline, $0.5 \mathrm{ml} \mathrm{H}_{2} \mathrm{SO}_{4}$ and $17.5 \mathrm{mg} \mathrm{CdCl}_{2}$ are mixed in $9 \mathrm{ml}$ double distilled water and the solution is placed in three electrode glass cell for electrochemical treatment. Synthesis has been carried out in two steps, firstly a current of $60 \mu \mathrm{A}$ has been kept constant for $300 \mathrm{~s}$ (schematic is shown in Figure 1). The electrode is then taken out and washed properly with distilled water. Again putting electrode into the shell and before starting the electro polymerization we injected $1.4 \mathrm{mg} / \mathrm{ml}$ solution of $\mathrm{Na}_{2} \mathrm{~S}$ into the cell which forms the suspensions of CdS nanoparticles in the mixture uniformly, and the similar treatment is done with $120 \mu \mathrm{A}$ current for next $300 \mathrm{~s}$ for the formation of PANI-(CdS-QD) composite on ITO. After synthesis electrode is rinsed thoroughly in distilled water, dried and stored at $4^{\circ} \mathrm{C}$.

\section{Immobilization of Cholesterol oxidase (ChOx) onto electrodes}

Cholesterol oxidase is covalently immobilized on the surface of prepared electrodes. For this purpose, $50 \mathrm{mg}$ EDC and $10 \mathrm{mg}$ NHS are mixed in $200 \mu \mathrm{l}$ ChOx added with $400 \mu \mathrm{l}$ distilled water. $30 \mu \mathrm{l}$ of this solution is spread on the surface of prepared electrode and then left the electrode inside a humid chamber for about four hours for the proper immobilization of enzyme on electrode surface.

\section{Photometric studies}

Photometric experiments have been carried out as a function of cholesterol concentration using PBS buffer $(50 \mathrm{mM}, \mathrm{pH} 7.4,0.9 \%$ $\mathrm{NaCl}$ ). These measurements have been made to estimate the enzyme activity, reproducibility and the interferent studies of the bioelectrode. To carry out photometric enzymatic assay of the immobilized ChOx, ChOx/PANI-(CdS-QD)/ITO bioelectrode has been dipped in $3 \mathrm{ml}$ PBS solution containing $20 \mu \mathrm{l} \mathrm{HRP}\left(1 \mathrm{mg} \mathrm{dl}^{-1}\right), 20 \mu \mathrm{l}$ o-dianisidine dye and $100 \mu \mathrm{l}$ of cholesterol. The difference between the initial and final absorbance value at $500 \mathrm{~nm}$ after $3 \mathrm{~min}$ incubation of cholesterol has been recorded and plotted.

\section{Instrumentation}

Scanning electron microscopy (SEM, Zeiss EVO 40) and transmission electron microscopy (JEOL-2100F) have been used to reveal the formation of CdS-QD, PANI/ITO, PANI-(CdS-QD)

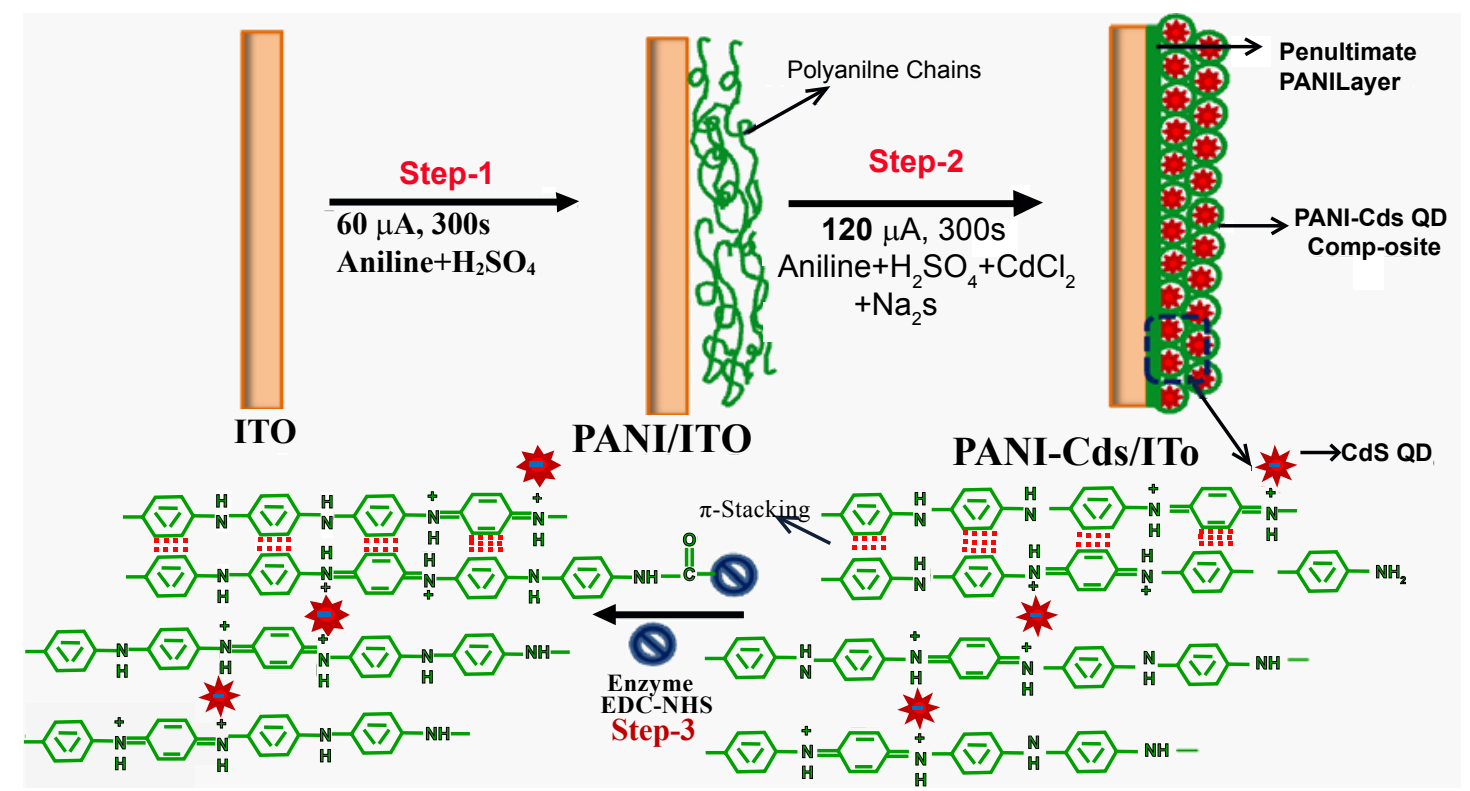

Figure 1: Fabrication of PANI-(CdS-QD)/ITO electrode by electropolymerization technique and ChOx immobilization by EDC-NHS chemistry. 
electrode and the immobilization of ChOx onto the PANI-(CdS-QD) matrix. Structural characterization of the prepared samples has been accomplised by UV-visible spectrophotometer (Model 2200DPCV, Phoenix) and Fourier transform infra-red (FT-IR) spectroscopy using Perkin-Elmer Spectrophotometer (model "Spectrum BX" using ATR accessory. Electrochemical investigations (CV and EIS) of the prepared electrodes have been carried out using an Autolab Potentiostat/Galvanostat (Eco Chemie, Netherlands) in a conventional three-electrode electrochemical cell consisting of $\mathrm{Ag} / \mathrm{AgCl}$ as reference electrode and platinum foil as the counter electrode. Electrochemical impedance spectroscopy (EIS) studies have been performed in the frequency range, $0.01-10^{5} \mathrm{~Hz}$ with amplitude of $5 \mathrm{mV}$ in PBS solution. Photometric measurements have been conducted using UV-Vis spectrophotometer, Phoenix-2200DPCV.

\section{Results and Discussion}

\section{TEM analysis of CdS quantum dots}

The morphology of the prepared CdS studied by the high resolution transmission electron microscopy (HRTEM) is shown in Figure 2. The existence of lattice planes clearly visible in the HRTEM image are indicative of crystallinity in CdS quantum dots. The TEM image shows the well dispersed CdS QDs and most of the dots have been examined to have the elliptical shape with diameter ranging from 4 to $7 \mathrm{~nm}$. The inset shows the HRTEM image of a single quantum dot with clearly visible lattice planes having the inter-planar distance around $0.133 \mathrm{~nm}$ between the two consecutive planes.

\section{UV-visible analysis}

Figure 3 shows the UV-Vis absorption spectra of CdS quantum dots (i), PANI/ITO electrode (ii) and PANI-(CdS-QD)/ITO electrode (iii), respectively. In the UV-Vis spectra of CdS solution in methanol, the absorption shoulder peak at $450 \mathrm{~nm}$ is assigned to the optical transition of the "exciton" in the first excitonic state and the significant blue shift in this peak with respect to bulk CdS $(520 \mathrm{~nm})$ corresponds to the formation of CdS within the diameter range of 4-5 nm due to quantum confinement effect [25]. The absorption spectrum of PANI shows bands around $355 \mathrm{~nm}$ and $420 \mathrm{~nm}$ corresponding to $\pi-\pi^{*}$ transition within the benzenoid moieties and due to the formation of a doping level owing to the 'exciton' transition, caused by inter-band charge transfer from benzenoid to quinoid moieties, respectively. The localized polaron peak around $807 \mathrm{~nm}$ indicates a compact coiled (tightly coiled chains) conformation of PANI revealing the presence of PANI in its conducting form. The in situ formation of PANI(CdS-QD) composite during electropolymerization is indicated by the appearance of additional hump around $450 \mathrm{~nm}$ (corresponds to absorption of $\mathrm{CdS}$ ). Furthermore the broadening and red shifting of the peak at $812 \mathrm{~nm}$ with remarkable decrease in the overall intensity of polaron absorption band implies the improved doping state of PANI(CdS-QD) composite. The broadening of this peak also reveals the transformation of PANI from its coiled conformation to the extended coil form [18].

\section{Fourier Transform Infra-red spectroscopy}

FT-IR spectra of PANI, PANI-(CdS-QD) composite and PANI(CdS-QD)-ChOx are depicted in figure 4 . The presence of peaks at 1490 and $1555 \mathrm{~cm}^{-1}$ are attributed to $\mathrm{C}=\mathrm{C}$ stretching of benzenoid and quinoid rings, respectively [19]. The appearance of peak around 1072 $\mathrm{cm}^{-1}$ (due to $\mathrm{C}-\mathrm{H}$ in plane bending vibration), $1302 \mathrm{~cm}^{-1}$ (corresponds to $\mathrm{C}-\mathrm{N}^{+}$stretching indicating secondary aromatic amine group in polymer main chain) and $3230 \mathrm{~cm}^{-1}$ attributed to the $\mathrm{N}-\mathrm{H}$ stretching vibrations [20], indicates the formation of PANI. The formation of the composite is indicated by the broadening of the $\mathrm{C}-\mathrm{N}^{+}$peak shows the interaction of CdS quantum dots with the $-\mathrm{NH}_{2}$ and $-\mathrm{NH}$ - groups of PANI. The FT-IR spectrum of the PANI-(CdS-QD) composite film exhibits enhanced quinoid (Q) band intensity with respect to benzenoid (B) band when compared to that of PANI without CdS. The observed changes reveal the richness of the composite with quinoid units that can be assigned to the interaction of positively charged $-{ }^{+} \mathrm{NH}=\mathrm{C}$ groups of quinoid units with the negatively charged skeleton of CdS quantum dots that are likely to promote the stabilization of the quinoid ring structure in PANI. The peaks around 1570 (60\% N-H Bending, 40\% C-N stretching) and $1657(80 \% \mathrm{C}=\mathrm{O}$ stretching $+10 \% \mathrm{C}-\mathrm{N}$ stretching $+10 \% \mathrm{~N}-\mathrm{H}$ Bending) in the FT-IR spectra of ChOx/PANI-(CdS-QD)/ ITO electrode reveals the successful immobilization of ChOx on this nanocomposite matrix.

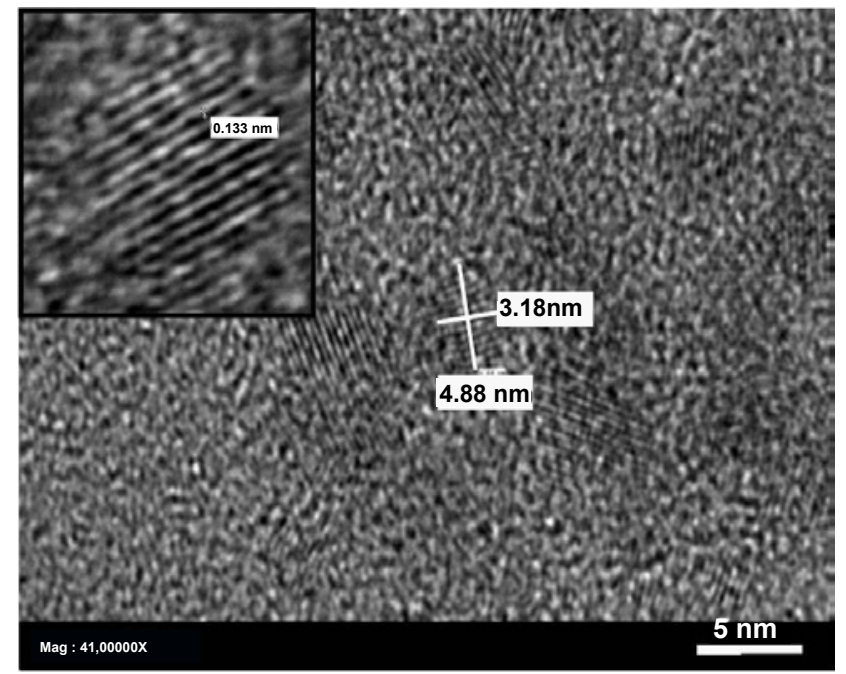

Figure 2: TEM micrograph of CdS quantum dots; inset shows magnified view of lattice spacing.

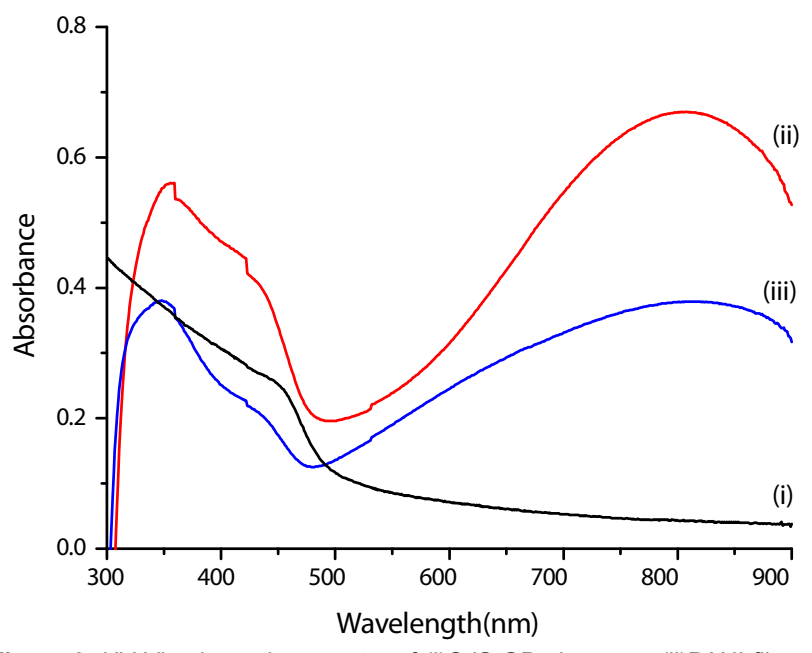

Figure 3: UV-Vis absorption spectra of (i)CdS-QDs in water, (ii)PANI film and (iii) PANI-(CdS-QD) electrode film 


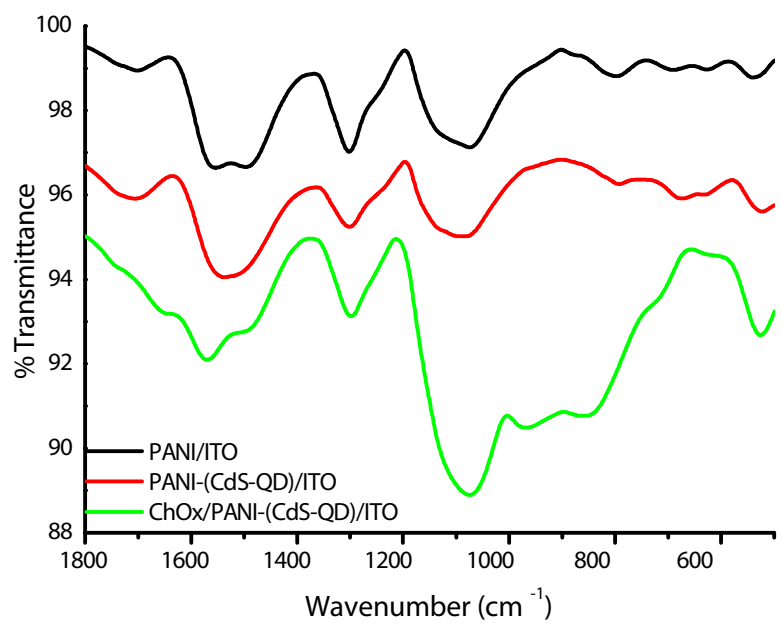

Figure 4: FT-IR spectra of PANI/ITO, PANI-(CdS-QD)/ITO and ChOx-PANI(CdS-QD)/ITO electrodes taken at the resolution of $1.01 \mathrm{~cm}^{-1}$ with 32 number of scans.

\section{SEM analysis}

The scanning electron microscopic (SEM) images of PANI/ITO, PANI-(CdS-QD)/ITO, ChOx/PANI-(CdS-QD)/ITO are shown in the figure 5. Figure 5(i) shows uniform globular morphology of PANI/ ITO film with globule diameter varies in the range of $200 \mathrm{~nm}$ to 500 $\mathrm{nm}$. The incorporation of CdS-QD within PANI matrix results in the generation of homogenous, densely packed nano-globular morphology of PANI-(CdS-QD)/ITO film (Figure 5 (ii)). These nano-globules show deviation in the range of 20 to $70 \mathrm{~nm}$ revealing as if QDs are acting as templates during the electrochemical polymerization of PANI thus resulting in its nano-structured deposition. The immobilization of ChOx is indicated by the masking of the nano-porous morphology of PANI-(CdS-QD)/ITO electrode with bright shining light shade macrostructures clearly visible on uniform smooth topology of PANI-(CdSQD) matrix (Figure 5 (iii)).

\section{Electrochemical Characterization Studies}

Electrochemical analysis of PANI/ITO and PANI-(CdS-QD)/ ITO electrode has been done using cyclic voltammetry $(\mathrm{CV})$ and electrochemical impedance spectroscopy (EIS). CV and EIS studies have been carried out using a three-electrode cell with platinum foil as counter and $\mathrm{Ag} / \mathrm{AgCl}$ as reference electrode in PBS (pH 7.0, $50 \mathrm{mM}$, $0.9 \% \mathrm{NaCl}$ ) on an Autolab Potentiostat/Galvanostat (Eco Chemie, Netherlands).

CV Analysis: To study the electrochemical behaviour, CV studies of PANI/ITO electrode and PANI-(CdS-QD)/ITO electrode have been investigated in the potential range of $-0.5 \mathrm{~V}$ to $0.5 \mathrm{~V}$ at the scan rate of $50 \mathrm{mVs}^{-1}$. The CV of PANI/ITO electrode shows redox behaviour with the anodic peak $(0.05 \mathrm{~V})$ and cathodic peak $(-0.2 \mathrm{~V})$ corresponds to the transition of PANI backbone from its leucoemeraldine state (reduced) to emeraldine state (partially oxidized). The CV of PANI-(CdS-QD)/ ITO composite electrode in figure 6(A) reveals enhancement of the anodic and cathodic peak currents from $0.074 \mathrm{~mA}$ to $0.093 \mathrm{~mA}$ and from $-0.115 \mathrm{~mA}$ to $-0.147 \mathrm{~mA}$, respectively, when compared to PANI/ ITO electrode. This enhancement in the current is indicative of fast
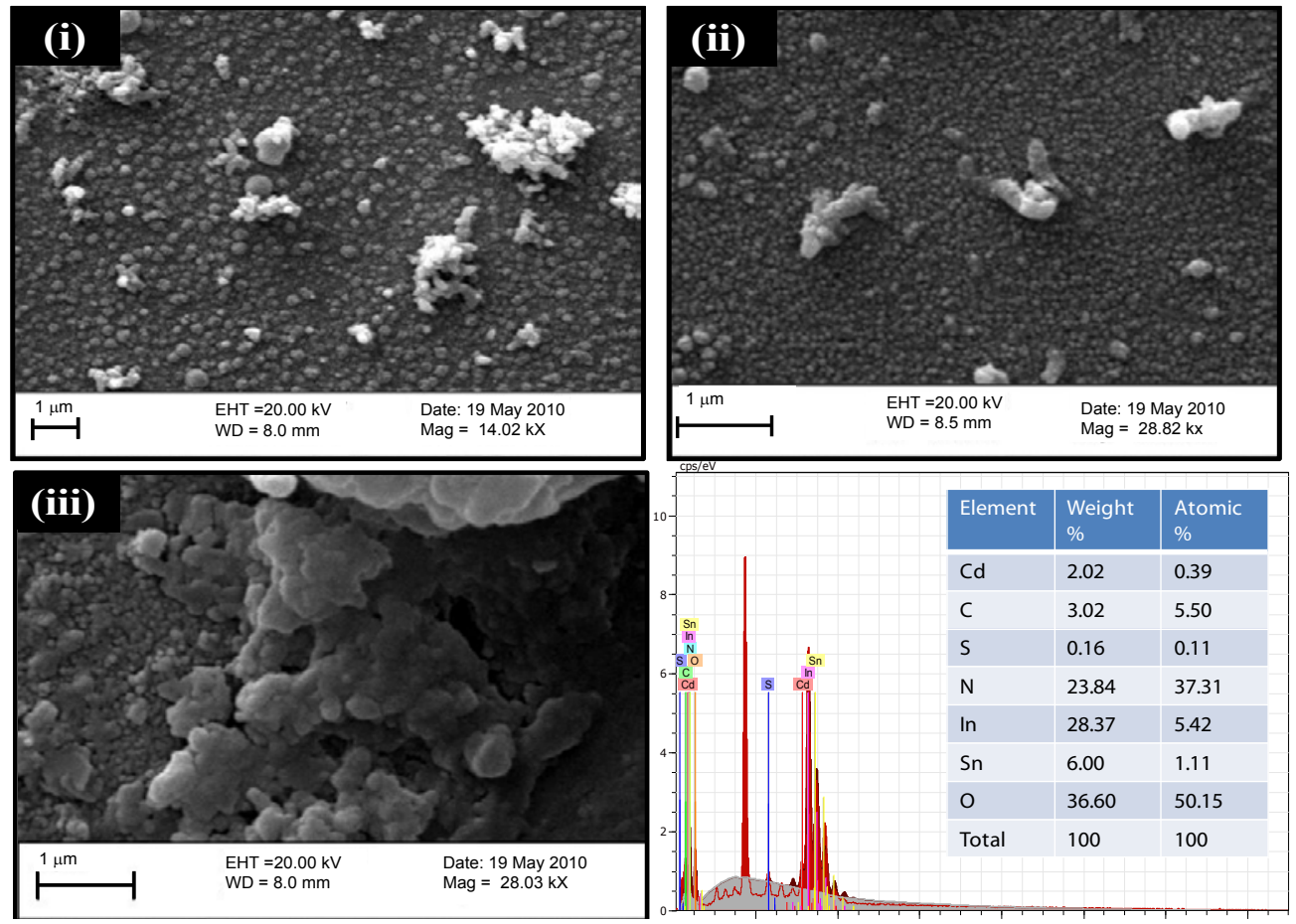

Figure 5: SEM micrograph of (i) PANI/ITO electrode; (ii) PANI-(CdS-QD)/ITO electrode; (iii) ChOx/PANI-(CdS-QD)/ITO bioelectrode and EDS analysis of PANI-(CdSQD)/ITO bioelectrode. 
Citation: Dhyani H, Dhand C, Malhotra BD, Sen P (2011) Polyaniline-CdS Quantum Dots Composite for Mediator Free Biosensing. J Biosens Bioelectron 3:112. doi:10.4172/2155-6210.1000112

Page 5 of 9

electron transport and increased charge transport in the parallel interface of electrolyte solution and PANI-(CdS-QD)/ITO electrode. This result can be attributed to the enhanced surface concentration of redox species $(\Gamma)$ in the composite. To verify this, concentration of the redox species has been calculated using the Laviron's equation [26] as given below

$$
E_{p a}=E^{o}+\frac{R T}{\alpha n F}\left[\ln \frac{R T}{\alpha n F} K_{o}-\ln v\right]
$$

According to the above equation, the value of $2.303 \mathrm{RT} / \mathrm{anF}$, where $\alpha$ is the transfer coefficient, $\mathrm{F}$ is the Faraday constant $\left(96485.34 \mathrm{C} \mathrm{mol}^{-}\right.$ $\left.{ }^{1}\right), \mathrm{R}$ is the gas constant $\left(8.314 \mathrm{~J} \mathrm{~mol}^{-1} \mathrm{~K}^{-1}\right), \mathrm{n}$ is the number of electrons transferred and $\mathrm{T}$ is the temperature, for PANI/ITO and PANI-(CdSQD)/ITO can be given by the slope of the plot of log scan rate $(v)$ versus $\mathrm{E}_{\mathrm{pa}}$ at different $v$ values.

For PANI/ITO and PANI-(CdS-QD)/ITO electrodes, the anodic peak potential $\left(E_{p a}\right)$ varies linearly with logarithm of $v$ (scan rate, data not shown) and follows the equation $2^{\text {nd }} \& 3^{\text {rd }}$, respectively.

$$
\begin{aligned}
& \mathrm{E}_{\mathrm{pa}}(\mathrm{PANI} / \mathrm{ITO})=0.092 \log v\left(\mathrm{Vs}^{-1}\right)+0.0404 ; \mathrm{R}=0.92 ; \mathrm{SD}=0.0 \\
& 094
\end{aligned}
$$

$\mathrm{E}_{\mathrm{pa}}(\mathrm{PANI}-(\mathrm{CdS}-\mathrm{QD}) / \mathrm{ITO})=0.1127 \log v\left(\mathrm{Vs}^{-1}\right)+0.0348 ; \mathrm{R}=$ $0.996 ; \mathrm{SD}=0.00372$

Considering equation (1), (2) and (3), the value of 2.303RT/anF for PANI/ITO and PANI-(CdS-QD)/ITO can be given as

$$
\begin{aligned}
& \frac{2.303 R T}{\alpha n F}=0.19192(\text { For PANI/ITO }) \\
& \frac{2.303 R T}{\alpha n F}=0.92(\text { For PANI-(CdS-QD)/ITO) }
\end{aligned}
$$

The value of 2.303RT/anF can be used to calculate the total surface concentration of the redox species $(\Gamma)$ onto PANI/ITO and PANISWCNT/ITO electrode by using equation given below

$$
I_{p}=\frac{n^{2} F^{2} \Gamma v A}{4 R T}
$$

where $\mathrm{I}_{\mathrm{p}} / \nu$ can be calculated from the slop of $\mathrm{I}_{\mathrm{p}} \mathrm{vs.} v$ plot [27]

The total surface concentration of redox species is found to be $3.211 \times 10^{-5} \mathrm{~mol} \mathrm{~m}^{-2}$ for PANI-(CdS-QD)/ITO composite electrode, which is $\sim 16$ times to that of concentration for PANI/ITO electrode $\left(2.047 \times 10^{-6} \mathrm{~mol} \mathrm{~m}^{-2}\right)$.

This increase in the redox species supports strong interactions between the negatively charged quantum structures of CdS with the aromatic structures of PANI that helps in uncoiling of the otherwise folded chains of PANI also supported by UV-V is spectroscopy. In the extended open conformation of PANI, it is likely that more number of exposed moieties are available for oxidation leading to enhanced faradic current. Figure 6 (B \& C) shows CV of PANI/ITO and PANI(CdS-QD)/ITO electrode recorded at different scan rates $(40-110 \mathrm{mV}$
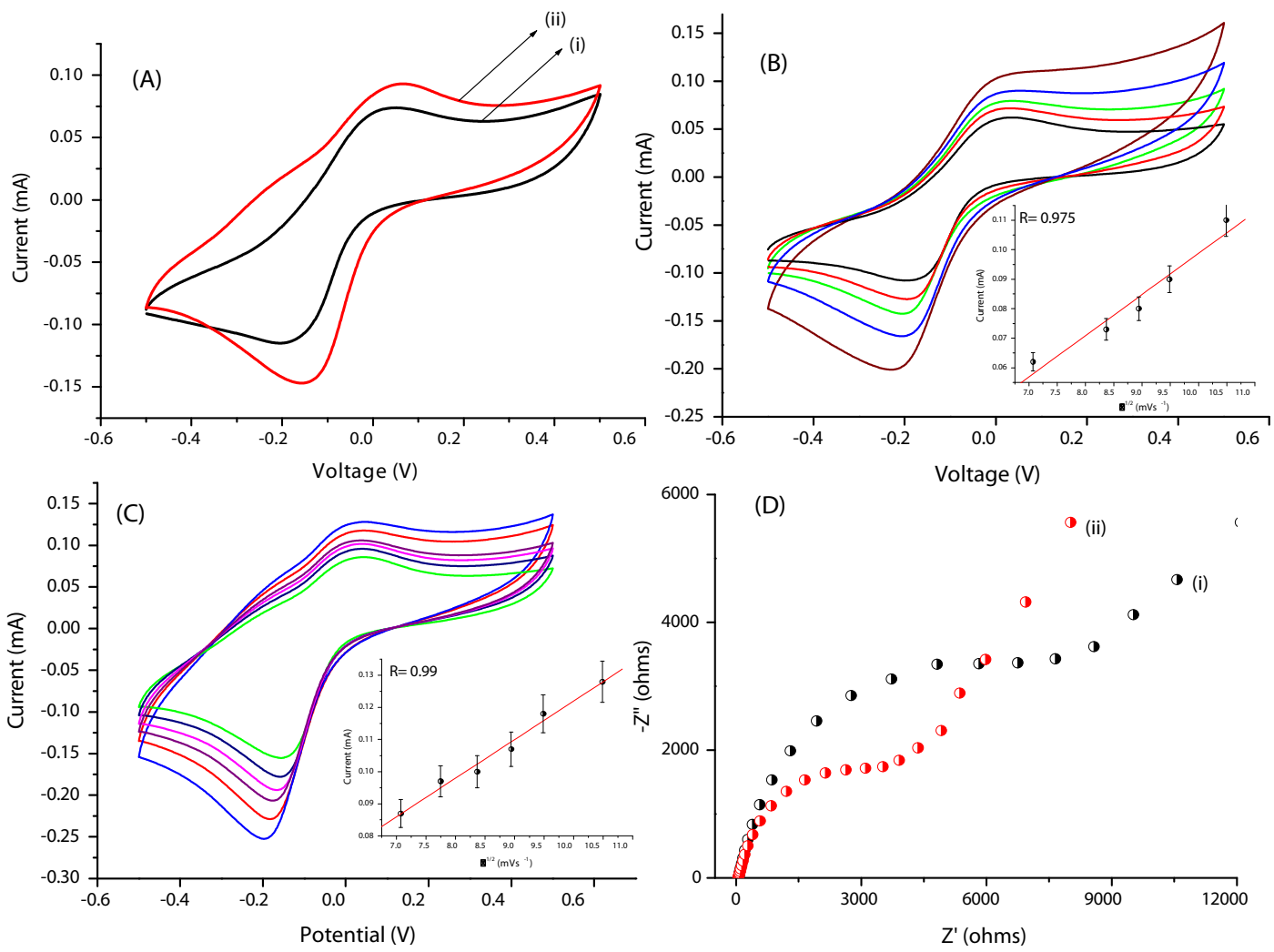

Figure 6: (A) Cyclic voltammogram of (i) PANI/ITO and (ii) PANI-(CdS-QD)/ITO electrode; (B \& C) CV of PANI/ITO electrode and PANI-(CdS-QD)/ITO electrode in PBS buffer at the scan rate from $40 \mathrm{mVs}^{-1}$ to $110 \mathrm{mVs}^{-1}$. Inset of fig 6 (B \& C) shows the variation of anodic peak current with respect to the square root of scan rate; (D) Electrochemical impedance spectra of (i) PANI/ITO (ii) PANI-(CdS-QD)/ITO electrode in PBS (50 mM, $\mathrm{pH} 7.0,0.9 \% \mathrm{NaCl}$ ) solution. 
$\left.\mathrm{s}^{-1}\right)$. Careful examination shows that while moving towards higher scan rate, there is a shift of the anodic peak towards more positive peak potential and cathodic peak in the reverse direction in case of PANI/ ITO electrode. However, negligible or no shift is observed in PANI(CdS-QD)/ITO system which is one of the primary criteria for the system to be reversible. Besides this, anodic and cathodic peak currents $\left(\mathrm{I}_{\mathrm{pa}}\right.$ and $\left.\mathrm{I}_{\mathrm{pc}}\right)$ show improved linear behaviour with respect to square root of scan rate $\left(v^{1 / 2}\right)$ in case of PANI-(CdS-QD) composite matrix (Regression coefficient $(\mathrm{r})=0.99)$ (inset of Figure $6(\mathrm{~B})$ ) than that of pure PANI matrix $(r=0.975)$ (inset of Figure $6(\mathrm{C})$ ) revealing that the electron-transfer processes are more diffusion controlled in case of PANI-(CdS-QD)/ITO electrode. The linear regression equations for PANI/ITO and PANI-(CdS-QD) electrode are given as Equation (7$10)$.

$$
\begin{aligned}
& \mathrm{I}_{\mathrm{pa}}(\mathrm{PANI} / \mathrm{ITO})=0.014 v^{1 / 2}\left(\mathrm{Vs}^{-1}\right)-0.04 ; \mathrm{r}=0.975 ; \mathrm{SD}=0.0046 \\
& \mathrm{I}_{\mathrm{pc}}(\mathrm{PANI} / \mathrm{ITO})=-0.00159 v^{1 / 2}\left(\mathrm{Vs}^{-1}\right)+0.0206 ; \mathrm{r}=-0.985 ; \mathrm{SD}=0.00 \\
& 709
\end{aligned}
$$

$\mathrm{I}_{\mathrm{pa}}(\mathrm{PANI}-(\mathrm{CdS}-\mathrm{QD}) / \mathrm{ITO})=0.012 v^{1 / 2}\left(\mathrm{Vs}^{-1}\right)+0.0198 ; \mathrm{r}=0.99 ; \mathrm{SD}$

$=0.00224$

$\mathrm{I}_{\mathrm{pc}}(\mathrm{PANI}-(\mathrm{CdS}-\mathrm{QD}) / \mathrm{ITO})=0.00166 v^{1 / 2}\left(\mathrm{Vs}^{-1}\right)+0.074 ; \mathrm{r}=-0.996$ $\mathrm{SD}=0.0037$
The above discussion indicates that the incorporation of CdS quantum dots not only enhances the charge transfer properties of PANI matrix but leads to overall improvement in the electrochemical behavior of the system.

Electrochemical impedance spectroscopy (EIS) studies: EIS studies have been done to further support the improved electrochemical response of PANI matrix on the incorporation of CdS-QDs. Figure 6 (D) shows that, in spite of similar shapes of the two Nyquist plots there is remarkable decrease in the diameter of the semicircle (indicative of charge transfer resistance) for the PANI-(CdS-QD) composite film. The smaller semicircle indicates that the charge transfer resistance $(6.32 \mathrm{~K} \Omega$ ) for PANI-(CdS-QD) composite film is nearly half to that of the PANI film $(12.6 \mathrm{~K} \Omega$ ). This enhanced charge transfer is likely to be due to the presence of hopping centres created by the semiconducting CdS-QD in the PANI matrix that helps in faster charge transfer via electrons from one polymer chain to the other and finally to the electrode (ITO) surface. Moreover, incorporation of QDs facilitate the open conformation of PANI resulting in easy charge transport.

\section{Response studies using cyclic voltammetric technique}

To show the potential application of observed enhanced
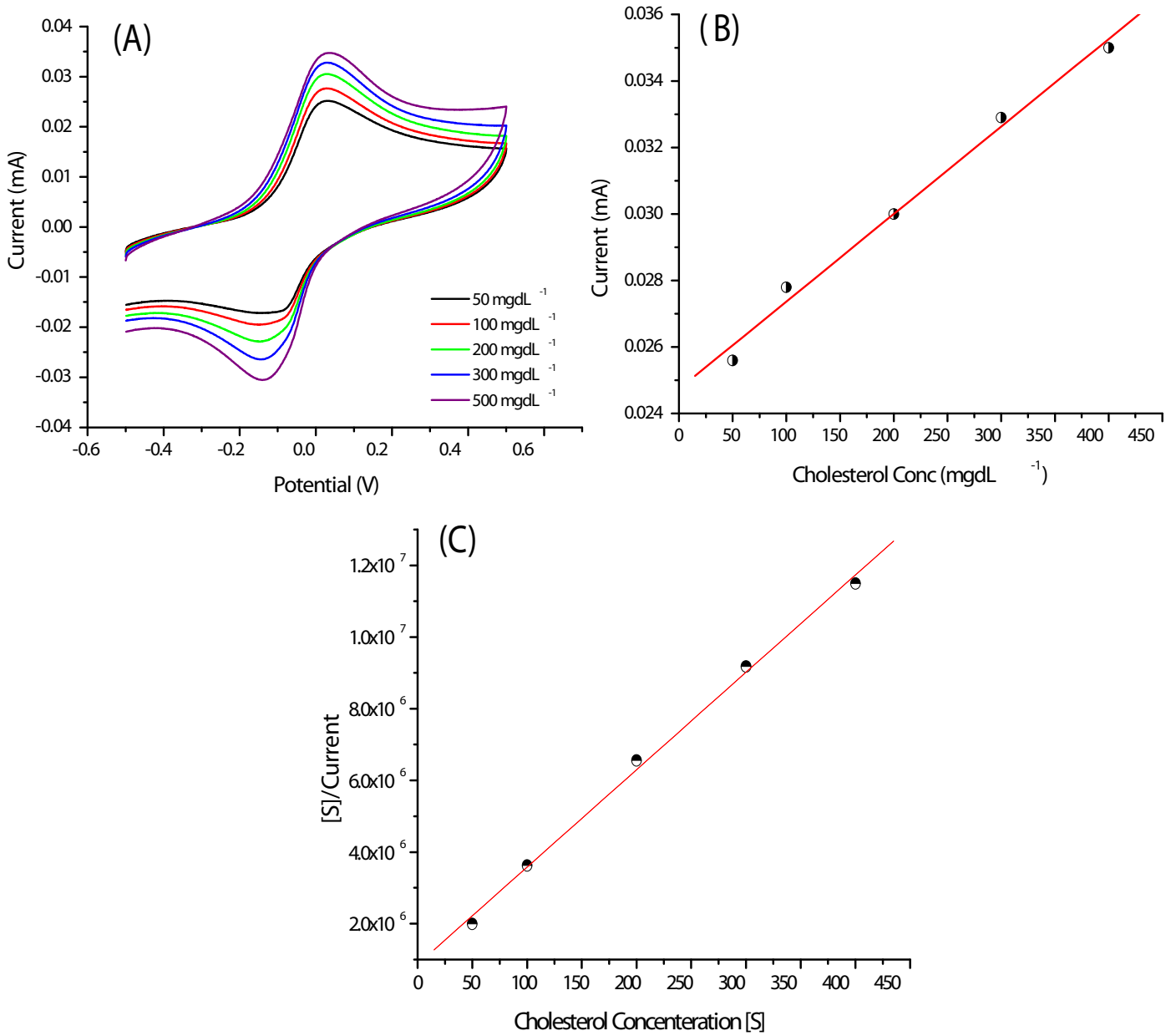

Figure 7: (A) CV recorded for ChOx/PANI-(CdS-QD)/ITO bioelectrode as a function of concentration of cholesterol (50 to $500 \mathrm{mg} \mathrm{dL-1)} \mathrm{in} \mathrm{PBS} \mathrm{(50} \mathrm{mM,} \mathrm{pH} 7.4,0.9 \%$ $\mathrm{NaCl}$ ) solution at the scan rate of $30 \mathrm{mV} / \mathrm{S}$; (B) calibration plots derived from $\mathrm{CV}$ measurements at $0.03 \mathrm{~V}$ as a function of cholesterol concentration; (C) Hanes plot between the substrate concentration and substrate concentration/current value obtained from plot $\mathrm{A}$. 
electrochemical properties of the PANI-(CdS-QD) composite, amperometric response studies of fabricated ChOx/PANI-(CdSQD)/ITO bioelectrode have been carried out using CV studies in PBS in the range from -0.5 to $0.5 \mathrm{~V}$ (Figure $7(\mathrm{~A})$ ). During the response measurement, an anodic peak is observed around $0.03 \mathrm{~V}$ in $\mathrm{CV}$ which shows continuous increase in its intensity with increasing cholesterol concentration. The anodic peak seen around $0.03 \mathrm{~V}$ corresponds to the oxidation of PANI integrated within the matrix, and its increase with increased cholesterol concentration suggests that $\mathrm{ChOx}$ gets electrically contacted by PANI-(CdS-QD) modified ITO electrode. It may be noted that no peak is observed relating to the oxidation of $\mathrm{H}_{2} \mathrm{O}_{2}$ in the range of 0.5 to $0.7 \mathrm{~V}$ indicating that there is direct transfer of electrons from the reduced ChOx enzyme to the PANI-(CdS-QD) matrix during the biochemical reaction. Figure 7(B) shows plot of anodic peak current at $0.03 \mathrm{~V}$ for ChOx/PANI-(CdS-QD)/ITO bioelectrode as a function of cholesterol concentration. It can be seen that ChOx/PANI-(CdS-QD)/ ITO bioelectrode can detect cholesterol in the range of 50 to $500 \mathrm{mg}$ $\mathrm{dL}^{-1}$ with detection limit of $47.9 \mathrm{mg} \mathrm{dL}^{-1}$ and response time of $20 \mathrm{~s}$. The value of sensitivity calculated from linear region of the calibration curve is $2.63 \times 10^{-5} \mathrm{~mA} \mathrm{mg}^{-1} \mathrm{dL}^{-1}$, with linear regression coefficient $(\mathrm{r})$ as 0.995 . The equation for the line of regression is given by:

Current $(\mathrm{mA})=0.0247 \mathrm{~mA}+\left[2.63 \times 10^{-5}\left(\mathrm{mAmg}^{-1} \mathrm{dL}^{-1}\right)\right] \times$ [Cholesterol Conc $\left(\mathrm{mgdL}^{-1}\right)$ ]

This high sensitivity of $2.63 \times 10^{-5} \mathrm{mAmg}^{-1} \mathrm{dL}^{-1}$ and low response time of $20 \mathrm{~s}$ reveals enhanced bioelectrocatalytic activity of the enzyme on PANI-(CdS-QD)/ITO electrode due to the enhanced charge transfer properties of the composite matrix.

The apparent Michaelis-Menten kinetic parameter $\left(K_{m}^{a p p}\right)$ of the enzymatic reaction, that determines the affinity of enzyme with the bioanalyte, has been estimated using Hanes plot i.e. a plot between analyte concentration [S] and [S]/Current (Figure $7(\mathrm{C})$ ). The $K_{m}^{a p p}$ value for the immobilized enzyme has been found to be $0.82 \mathrm{mM}$. The observed lower value of $K_{m}^{a p p}$ shows enhanced affinity of the enzyme with the cholesterol on this nanocomposite matrix. Also, this PANI-(CdSQD) matrix prepared by electrochemical technique may be helping the immobilized enzyme to achieve better conformation for faster enzymatic reaction resulting in enhancement of enzymatic activity.

\section{Photometric studies of ChOx/PANI-(CdS-QD)/ITO bioelectrode using UV-Vis technique}

Figure 8(A) shows photometric response of the ChOx/PANI(CdS-QD)/ITO bioelectrode as a function of cholesterol concentration. The value of absorbance has been found to increase with increased cholesterol concentration [50-500 $\left.\mathrm{mgdl}^{-1}\right]$. The results have been utilized to estimate the amount of immobilized enzyme units using equation $a_{a p p}^{e n z}\left(\mathrm{U} \mathrm{cm}^{-2}\right)=\mathrm{AV} / \varepsilon$ ts, where $\mathrm{A}$ is difference in absorbance before and after incubation, $\mathrm{V}$ is the total volume $\left(3.14 \mathrm{~cm}^{3}\right), \varepsilon$ is the millimolar extinction coefficient ( 7.5 for o-dianisidine at $500 \mathrm{~nm})$, $\mathrm{t}$ is the reaction time $(\mathrm{min})$ and $\mathrm{s}$ is the surface area $\left(1 \mathrm{~cm}^{2}\right)$ of the electrode. The value of immobilized ChOx units has been estimated to be $10 \mathrm{x}$ $10^{-3} \mathrm{U} \mathrm{cm}^{-2}$, indicating that $10 \times 10^{-3} \mathrm{U} \mathrm{cm}^{-2}$ units of enzyme actively participate in the biochemical reaction.

Figure $8(\mathrm{~B})$ shows the effect of interferents on the observed response of ChOx/PANI-(CdS-QD)/ITO electrode. In this figure, the first bar (cholesterol) shows the change in absorbance obtained with $200 \mathrm{mgdL}^{-1}$ of cholesterol when compared with absorbance

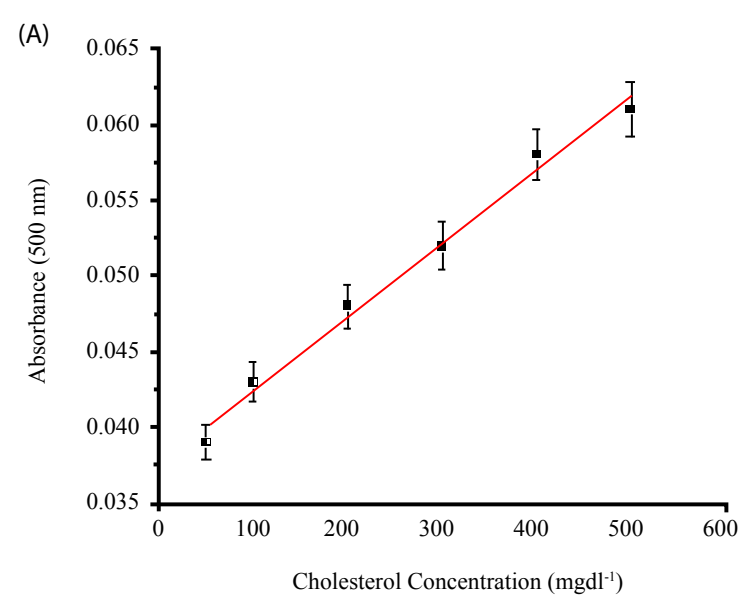

(B)

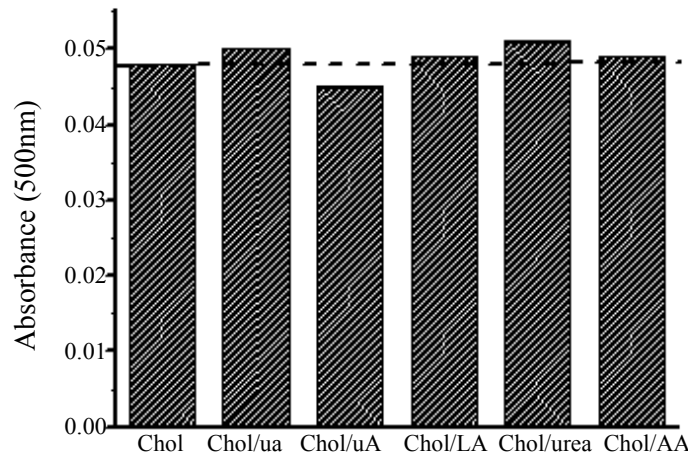

Figure 8: (A) Photometric response of ChOx/PANI-(CdS-QD)/ITO bioelectrode as a function of cholesterol concentration; (B) Effect of various interferents on the response of ChOx/PANI-(CdS-QD)/ITO bioelectrode.

obtained for $0 \mathrm{mM}$ of cholesterol concentration. The remaining bars show the absorbance corresponding to the mixture of cholesterol and interferents in 1:1 ratio. The straight line parallel to $\mathrm{X}$-axis shows the variation in the presence of desired interferents, revealing a maximum of $6 \%$ interference. Studies revealed that the ChOx/PANI-(CdS-QD)/ ITO bioelectrode retains more than $90 \%$ of activity even after 7 weeks (data not shown) and has reusability of about 9 times. Table 1 shows the comparison of present matrix to some of the other reported matrices for cholesterol detection.

\section{Conclusions}

We have successfully fabricated nanocomposite films of PANI and CdS-QD using electrochemical polymerization technique. The nanocomposite film deposition involves in-situ formation of CdS quantum dots that may act as templates for the aniline eletropolymerization and thus resulting in nanostructured PANI-(CdS-QD) film deposition on the indium-tin-oxide (ITO) coated glass plates. UV-Visible absorption study shows the increased charge species on the PANI backbone leads the transformation of PANI from its coiled conformation to the extended coil form. CV and EIS studies reveal fast charge transport (2 folds) in the PANI-(CdS-QD) system as compared to the analogous PANI system which is attributed to the enhanced surface concentration of redox species ( 16 times) in the composite matrix. Moreover the semiconducting CdS-QD provides 'hopping centres' that helps in the faster charge transfer via electrons from one polymer chain to the other and finally to the electrode surface. This 
Citation: Dhyani H, Dhand C, Malhotra BD, Sen P (2011) Polyaniline-CdS Quantum Dots Composite for Mediator Free Biosensing. J Biosens Bioelectron 3:112. doi:10.4172/2155-6210.1000112

Page 8 of 9

\begin{tabular}{|c|c|c|c|c|c|c|c|}
\hline S. No. & Matrix & Linearity & Sensitivity & Respon-se Time & $\begin{array}{l}K_{\mathrm{m}}^{\text {app }} \\
(\mathrm{mM})\end{array}$ & Shelf Life & Reference \\
\hline 1 & $\begin{array}{c}\text { Electrochemically deposited } \\
\text { PANI }\end{array}$ & $100-400 \mathrm{mg} / \mathrm{dl}$ & $0.042 \mu \mathrm{Amg}^{-1} \mathrm{dL}^{-1}$ & $240 s$ & 1.94 & 6 weeks & [28] \\
\hline 2 & MWNTs & $19.3-231.6 \mathrm{mg} / \mathrm{dl}$ & $\begin{array}{c}0.559 \mu \mathrm{A} \\
\mathrm{cm}^{-2} \mathrm{mM}^{-1}\end{array}$ & - & 7.71 & - & [29] \\
\hline 3 & $\begin{array}{l}\text { MWCNT/Screen Printed } \\
\text { Carbon Electrode }\end{array}$ & $99.5-399$ mg/dl & $0.0059 \mu \mathrm{Amg}^{-1} \mathrm{dL}^{-1}$ & - & - & 9 weeks & [30] \\
\hline 4 & Gold electrode & $0-80 \mathrm{mg} / \mathrm{dl}$ & $0.13 \mu \mathrm{A} / \mathrm{mM}$ & $15 \mathrm{~s}$ & 2.94 & - & [31] \\
\hline 5 & ZnO Nanoparticles & $0.001-0.5 \mu \mathrm{M}$ & $23.7 \mu \mathrm{A} / \mu \mathrm{M}$ & - & 4.7 & - & [32] \\
\hline 6 & Chitosan- $\mathrm{SnO}_{2}$ nanocomposite & $0.26-10.36 \mathrm{mM}$ & $34.7 \mu \mathrm{Amg}^{-1} \mathrm{dL}^{-1} \mathrm{~cm}^{-2}$ & - & 3.8 & 12 weeks & [33] \\
\hline 7 & $\begin{array}{l}\text { PANI-(CdS-QD) } \\
\text { Nanocomposite }\end{array}$ & $50-500$ & $2.63 \times 10^{-5} \mathrm{~mA} \mathrm{mg}^{-1} \mathrm{dL}^{-1}$ & $20 \mathrm{~s}$ & 0.82 & 7 weeks & Present Work \\
\hline
\end{tabular}

Table 1: Characteristics of PANI-(CdS-QD) electrode along with those reported in literature for cholesterol detection.

improved electrochemical behavior has been used to enhance the bioelectrocatalytic activity of the enzymes to obtain better biosensing characteristics. The response studies, carried out using CV technique, reveal that this ChOx/PANI-(CdS-QD)/ITO bioelectrode can be used to detect cholesterol in the concentration range of 50 to $500 \mathrm{mgdL}^{-1}$ with good detection limit $\left(47.8 \mathrm{mgdL}^{-1}\right)$ and low $K_{m}^{a p p}$ value $(0.82$ $\mathrm{mM}$ ). This matrix can further be explored for the detection of other analytes (e.g. glucose, lactic acid, urea, antigens, antibodies etc.).

\section{Acknowledgements}

The authors thank Director NPL, New Delhi India for providing the facilities. We also thank Advanced instrumentation and research facility (AIRF), JNU, New Delhi for the TEM, XRD and SEM analysis. Hemant Dhyani \& Chetna Dhand thank CSIR-India for award of Research Fellowships.

\section{References}

1. Malhotra BD, Chaubey A, Singh SP (2006) Prospects of conducting polymers in biosensors. Analytica Chimica Acta 578: 59-74.

2. Sai VVR, Mahajan S, Contractor AQ, Mukherji S (2006) Immobilization of antibodies on polyaniline films and its application in a piezoelectric immunosensor. Anal Chem 78: 8368-8373.

3. Dhand C, Arya SK, Datta M, Malhotra BD (2008) Polyaniline-carbon nanotube composite film for cholesterol biosensor. Anal Biochem 383: 194-199.

4. Resch-Genger U, Grabolle M, Cavaliere-Jaricot S, Nitschke R, Nann T (2008) Quantum dots versus organic dyes as fluorescent labels. Nature Methods 5 : $763-775$.

5. Palma RM, Manso M, Costa VT (2009) Optical Biosensors Based on Semiconductor Nanostructures. Sensors 9: 5149-5172.

6. Frasco MF, Chaniotakis N (2009) Semiconductor Quantum Dots in Chemical Sensors and Biosensors. Sensors 9: 7266-7286.

7. Liu Q, Lu X, Li L, Yao X, Li J (2007) Direct electrochemistry of glucose oxidase and electrochemical biosensing of glucose on quantum dots/carbon nanotubes electrodes. Biosens Bioelectron 22: 3203-3209.

8. Tang L, Zhu Y, Yang X, Sun J, Li C (2008) Self-assembled CNTs/CdS/ dehydrogenase hybrid-based amperometric biosensor triggered by photovoltaic effect. Biosens Bioelectron 24: 319-323.

9. Yuan J, Guo W, Wang E (2008) Quantum dots-bienzyme hybrid system for the sensitive determination of glucose. Biosensors \& Bioelectronics 23: $1567-$ 1571.

10. Huang CP, Liu SW, Chen TM, Li YK (2008) A new approach for quantitative determination of glucose by using CdSe/ZnS quantum dots. Sensors and Actuators B: Chemical 130: 338-342.

11. Koneswaran M, Narayanaswamy R (2009) Mercaptoacetic acid capped CdS quantum dots as fluorescence single shot probe for mercury(II). Sensors and Actuators B 139: 91-96.
12. Falcaro P, Hill AJ, Nairn KM, Jasieniak J, Mardel JI, et al. (2011) A new method to position and functionalize metal-organic framework crystals. Nat Commun 2: 237.

13. Huang Y, Zhang W, Xiao H, Li G (2005) An electrochemical investigation of glucose oxidase at a CdS nanoparticles modified electrode. Biosensors \& Bioelectronics 21: 817-821

14. Hickey SG, Riley DJ (1999) Distance Dependent Electron Transfer in Gold/ Spacer/Q-CdSe-Assemblies. J Phys Chem B 103: 4599-4602.

15. Li Z, Du Y (2003) Biomimic synthesis of CdS nanoparticles with enhanced luminescence. Materials Letters 57: 2480-2484.

16. Gao Y, Tonizzo A, Walser A, Potasek M, Dorsinville R (2008) Enhanced optical nonlinearity of surfactant-capped CdS quantum dots embedded in an optically transparent polystyrene thin film. Appl Phys Lett 92: 033106.

17. Seoudi R, Kamal M, Shabaka AA, Abdelrazek EM, Eisa W (2010) Synthesis, characterization and spectroscopic studies of CdS/polyaniline core/shell nanocomposite. Synthetic Metals 160: 479-484.

18. Khiew PS, Huang NM, Radiman S, Ahmad MS (2004) Synthesis and characterization of conducting polyaniline-coated cadmium sulphide nanocomposites in reverse microemulsion. Materials Letters 58: 516- 521.

19. Kulkarni MV, Viswanath AK, Marimuthu R, Seth T (2004) Synthesis and characterization of polyaniline doped with organic acids. J Polym Sci A Polym Chem 42: 2043-2049.

20. Versiane O, Rodrigueb BL, Ramos JM, Téllez CA, Felcman J (2006) Synthesis molecular structure and vibrational spectra of a dimeric complex formed by cobalt and glycine. Spectrochim Acta A 65: 1112-1119.

21. Singh N, Kulkarni MV, Lonkar SP, Viswanath AK, Khanna PK (2007) CdS / Polyaniline Nanocomposites: Synthesis and Characterization. Synthesis and Reactivity in Inorganic, Metal-Organic, and Nano-Metal Chemistry 37: 153-159.

22. Chandrakanthi RLN, Careem MA (2002) Preparation and characterization of $\mathrm{CdS}$ and $\mathrm{Cu}_{2} \mathrm{~S}$ nanoparticle/polyaniline composite films. Thin Solid Films 417 $51-56$

23. Godovsky DY, Varfolomeev AE, Zaretsky DF, Chandrakanthi RLN, Kündig A, et al. (2001) Preparation of nanocomposites of polyaniline and inorganic semiconductors. J Mater Chem 11: 2465-2469.

24. Khanna PK, Kulkarni MV, Singh N, Lonkar SP, Subbarao VVVS, et al. (2006) Synthesis of $\mathrm{HCl}$ doped polyaniline-CdS nanocomposite by use of organometallic cadmium precursor. Materials Chemistry and Physics 95: 24 28.

25. Nakanishi T, Ohtani B, Uosaki K (1998) Distance Dependent Electron Transfer in Gold/Spacer/Q-CdSe-Assemblies. J Phys Chem B 102: 1571-1577.

26. Zhuang Q, Chen J, Chen J, Lin X (2008) Electrocatalytical properties of bergenin on a multi-wall carbon nanotubes modified carbon paste electrode and its determination in tablets. Sensors and Actuators B 128: 500-506.

27. Hu G, Zhang D, Wu W, Yang Z (2008) Selective determination of dopamine in the presence of high concentration of ascorbic acid using nano-Au selfassembly glassy carbon electrode. Colloids Surf B Biointerf 62: 199-205. 
Citation: Dhyani H, Dhand C, Malhotra BD, Sen P (2011) Polyaniline-CdS Quantum Dots Composite for Mediator Free Biosensing. J Biosens Bioelectron 3:112. doi:10.4172/2155-6210.1000112

28. Singh S, Solanki PR, Pandey MK, Malhotra BD (2006) Cholesterol biosensor based on cholesterol esterase, cholesterol oxidase and peroxidase immobilized onto conducting polyaniline films. Sens Actuators B 115: 534-541.

29. Guo M, Chen J, Li J, Nie L, Yao S (2004) Carbon Nanotubes-Based Amperometric Cholesterol Biosensor Fabricated Through Layer-by-Layer Technique. Electroanalysis 16: 1992-1998.

30. Li G, Liao JM, Hu GQ, Ma NZ, Wu PJ (2005) Study of carbon nanotube modified biosensor for monitoring total cholesterol in blood. Biosens Bioelectron 20: 2140-2144.
31. Parra A, Casero E, Pariente F, Vazquez L, Lorenzo E (2007) Sens Actuators B 124: 30-37.

32. Umar A, Rahman MM, Vaseem M, Hahn YB (2008) Ultra-sensitive cholestero biosensor based on low-temperature grown $\mathrm{ZnO}$ nanoparticles. Electrochem Commun 11: 118-121.

33. Ansari AA, Kaushik A, Solanki PR, Malhotra BD (2009) Electrochemical Cholesterol Sensor Based on Tin Oxide-Chitosan Nanobiocomposite Film. Electroanalysis 21: 965-972. 